\title{
A Conceptual Framework of the Way Forward to a Community Pharmacist-General Practitioner Collaborative Medication Therapy Management Model for Chronic Diseases in Malaysian Primary Care: A Qualitative Study
}

\author{
Naeem Mubarak (D) \\ Sarwat Ali Raja' \\ Asma Sarwar Khan ${ }^{1,2}$ \\ Sabba Kanwal' \\ Nasira Saif-ur-Rehman' \\ Muhammad Majid Aziz' \\ Irshad Hussain ${ }^{3}$ \\ Ernieda Hatah (iD ${ }^{4}$ \\ Che Suraya Zin $\mathbb{D}^{5}$ \\ 'Department of Pharmacy Practice, \\ Lahore Medical \& Dental College, \\ University of Health Sciences, Lahore, \\ Punjab, Pakistan; ${ }^{2}$ Department of \\ Pharmacy Practice, University of Health \\ Sciences, Lahore, Punjab, Pakistan; \\ ${ }^{3}$ Department of Pharmacy, Shaheed \\ Mohtarma Benazir Bhutto Medical \\ University, Larkana, Sindh, Pakistan; \\ ${ }^{4}$ Department of Pharmacy, The National \\ University of Malaysia, Bangi, Malaysia; \\ ${ }^{5}$ Kulliyyah of Pharmacy, International \\ Islamic University, Kuantan, Malaysia
}

Correspondence: Naeem Mubarak Lahore Medical \& Dental College,

University of Health Sciences, Tulspura,

North Canal Bank, Lahore, 53400,

Pakistan

Tel +92 42-37392208

Email naeem.mubarak@Imdc.edu.pk

Che Suraya Zin

Universiti Islam Antarabangsa, Malaysia Kampus Kuantan, Pahang Darul Makmur, Jalan Sultan Ahmad Shah, Bandar Indera Mahkota, Kuantan, Pahang, 25200,

Malaysia

Tel +60 I I-I488I605

Email chesuraya@iium.edu.my

Background: There is a growing global interest in formulating such policies and strategic plans that help devise collaborative working models for community pharmacists (CPs) and general practitioners (GPs) in primary care settings.

Objective: To conceptualize a stakeholder-driven framework to improve collaboration between CPs and GPs in Malaysian primary care to effectively manage medicines in chronic diseases.

Design and Setting: A qualitative study that involved individual semi-structured interviews of the leadership of various associations, guilds, and societies representing CPs, GPs, and Nurses in Malaysia.

Methods: This study collected and reported data in accordance with the guidelines of the Consolidated Criteria for Reporting of Qualitative Studies. Key informants were recruited based on purposive (expert) sampling. Interviews were transcribed verbatim and data were coded based on the principles of thematic analysis in NVivo.

Results: A total of 12 interviews ( 5 CPs, 5 GPs, and 2 nurses) were conducted. Five themes emerged: Theme 1 highlighted a comparison of community pharmacy practice in Malaysia and developed countries; Theme 2 involved current practices in Malaysian primary care; Theme 3 encompassed the advantages of CP-GP collaboration in chronic diseases; Theme 4 highlighted the barriers which impede collaboration in Malaysian primary care; and Theme 5 delineated the way forward for CP-GP collaboration in Malaysia.

Conclusion: The actionable insights obtained from the Malaysian stakeholders offered an outline of a framework to enhance collaboration between CPs and GPs in primary care. Generally, stakeholders were interested in $\mathrm{CP}-\mathrm{GP}$ collaboration in primary care and identified many positive roles performed by $\mathrm{CPs}$, including prescription review, adherence support, and patient education. The framework of the way forward includes: separation of CP and GP roles through a holistic revision of relevant legislation to grant an active role to CPs in chronic care; definition of protocols for collaborative practices; incentivization of both stakeholders (CPs and GPs); and design and implementation of an effective regulatory mechanism whereby the Malaysian Ministry of Health may take a leading role.

Keywords: community pharmacist, general practitioner, chronic disease, collaborative care, Malaysia, qualitative research medicine management 


\section{Plain Language Summary How does this fit in?}

What was previously known?

- Effective chronic disease management requires optimal medicine management. In turn, this needs interprofessional collaboration. Here, such collaboration is widely thought of as a desirable model of practice in primary care. Here, the goal remains delivering a more diverse skill mix to meet the complex demands of chronic patients.

- Even so, there continues to be a general absence of stakeholder-driven frameworks that can conceptualize a way forward to enhanced collaboration among GPs and CPs in primary care in developing countries.

What does this study add?

- To our knowledge, this one-of-a-kind study recruited a geographically diverse panel of healthcare stakeholders comprised of the leadership of several associations, guilds, societies, and alliances that represent general practitioners, community pharmacists, and nurses across Malaysia.

- This study fills an important gap in the knowledge and offers actionable steps to enhance interprofessional collaboration between CPs and GPs in private primary care in Malaysia. Importantly, the study develops these action steps from insights gained through semi-structured interviews with relevant Malaysian healthcare stakeholders.

\section{Background}

The burden of chronic diseases has now grown to be a daunting challenge for the Malaysian healthcare system. In fact, Malaysia has a higher prevalence of chronic diseases than most of its neighbours, except Singapore. ${ }^{1}$ Optimal chronic disease management requires interprofessional collaboration and utilization of the expertise of different healthcare professionals. This is also demonstrated in the growing global interest in policies and strategic plans that seek to enhance interprofessional collaboration and to deliver a more diverse skill mix to chronic patients in primary care. ${ }^{2-4}$

The Malaysian healthcare system is two-tiered. It comprises of a heavily subsidized public sector and a non-subsidized, rapidly-expanding, private sector. In Malaysia, primary care — both in the private and the public sector — bears the burden of chronic diseases. ${ }^{5}$ Here, these tiers are working according to entirely different models. In the public sector, primary care is provided through community clinics, such as "Klinik Kesihatan" (that serves as the first point of care), "Polyclinics" (an upgraded and extended version of Klinik Kesihatan), "Klinik Desa" (that provides antenatal and postnatal care), and "1 Malaysia Clinic" (now rebranded as community clinics and cover the relatively remote areas). In Malaysia, a medical graduate who owns a private clinic after completion of four years' service in public hospitals is commonly referred to as a general practitioner (GP). ${ }^{6,7}$ In the public sector, there is a satisfactory level of collaboration between different healthcare professionals. In addition, the practice of "dispensing separation" exists within the public sector. 8 Here, dispensing separation (DS) refers to a practice where prescribers such as GPs prescribe medicines (generics) as per specified formulary and pharmacists dispense medicines and perform counselling.

Conversely, in the private sector, primary care is comprised of GPs' clinics, nursing homes, mental health clinics, and community pharmacies. Unlike in the public sector, DS does not exist within the private sector. ${ }^{10}$ Hence, GPs prescribe as well as dispense medications. On the other hand, the community pharmacists (CPs) represent a subgroup of pharmacists in the private sector who are mainly involved in selling over-the-counter drugs or cosmetics at retail outlets commonly referred as pharmacies. As the law permits a GP to dispense medications through a clinic, the number of prescriptions received by CPs are limited. ${ }^{11}$ As a result, patients remain deprived of input from a skilled professional (that is, CP) who could contribute positively to prescription review or adherence improvement amongst chronic patients based on their knowledge, skills, and training. Collaboration between GPs and CPs is rare in the private sector; rather, the situation has turned into a conflict or business rivalry. Here, it is important to note that, since more than $41 \%$ of Malaysians seek treatment in the private sector, addressing such issues and resolving potential conflicts remains a pressing concern. ${ }^{12,13}$

Despite the existence of many successful collaborative healthcare models in developed countries, collaboration is still not a common practice in primary care in many upper-middle-income countries, including Malaysia. $^{12,13}$ The preceding two decades have witnessed an inadequate response of the Malaysian primary care system (especially in the private sector) to the 
delivery of well-coordinated interventions to improve management of medicines in chronic diseases largely due to poor interprofessional collaboration. ${ }^{5,10}$ Nevertheless, every country has a different culture and health-seeking behaviours and socio-political dynamics. Fostering a culture of interprofessional collaboration has remained a complex challenge. A key issue, here, has been reconciling the different training backgrounds of relevant stakeholders and positional stakes in the given healthcare system. Recently, a Delphi survey aimed to build consensus among healthcare stakeholders in Malaysia and laid emphasis on $\mathrm{CP}-\mathrm{GP}$ collaboration for chronic disease management. ${ }^{14}$ However, lack of a qualitative research aspect as well as the inherent limitations of the Likert scale-based survey design used in the study impeded true exploration of the comments of concerned stakeholders. These comments (Table S1) generated further questions on the issue at hand and need further clarification of the stakeholders. In this scenario, a qualitative enquiry utilizing an interpretivist approach could yield a clear framework that interlinks different constructs to depict a holistic view of the way forward to improve interprofessional collaboration in primary care.

Against the above extrapolated background, the key objective of this study was to propose a conceptual framework - based on the insights of Malaysian healthcare stakeholders - to delineate the way forward to enhance interprofessional collaboration between GPs and CPs under a collaborative medication therapy management model (CMTM) in Malaysia.

\section{Methods}

The present study was conducted and reported in compliance with the Consolidated Criteria for Reporting Qualitative Research (COREQ) guidelines ( $\underline{\text { Table S2) }} .{ }^{15}$

\section{Selection and Recruitment of Experts/ Key Informants}

Purposive (expert) sampling was used to recruit key informants (KIs), that is, the stakeholders interviewed in this study. As all KIs were recruited from the sample used in the Delphi study, ${ }^{14}$ the selection criteria remained the same as previously reported (Figure S1), with a few additional inclusion criteria. The researchers determined that the KI must:
1. Have a Master's degree or, preferably, a $\mathrm{PhD}$ (in the case of academia), or a specialization (in the case of GPs).

2. Be available to give consent for a minimum onehour interview during specified dates.

3. Have a minimum of five years' experience working with a GP/CP in the relevant field.

GPs with a specialization (a higher qualification after an MBBS degree, such as Family Medicine Specialist in Malaysia) were preferred. This is because they are more experienced as frontline healthcare workers who are involved in chronic disease management in primary care. Thus, they are the most likely to have first-hand knowledge of the issues that concern this study.

In Malaysia, the BS Pharmacy degree entitles a candidate to run a community pharmacy. However, CPs do improve their qualifications, such as a Master's in Clinical Pharmacy Practice or a Master's in Community Pharmacy Practice, and hence enhance their knowledge and skills. Thus, we preferred any CP with a Master's degree.

Although the aim was to conceptualize a framework for improved collaboration between the two healthcare stakeholders (CPs and GPs), nurses' representatives were also taken on board. This was planned with a view to seek additional insights because nurses are involved in direct patient care in the GPs' clinics. Furthermore, the researchers view nurses as neutral observers of the purported conflict between CPs and GPs, and as an important stakeholder in any given healthcare system around the globe. Hence, nurses were added in the sample to further enrich the data.

The sample size for this study was determined by thematic saturation of the data. An honorarium worth 100 Malaysian Ringgit was granted to each stakeholder at the end of the interview.

\section{Semi-Structured Personal Interviews}

Semi-structured personal interviews were used as a tool for data collection. The format of the interview included open-ended questions to allow KIs to offer additional perspectives and thus enable exploration of various aspects of the way-forward to a CMTM model in Malaysian primary care setting.

\section{Setting}

All face-to-face interviews were conducted in the respective KIs' offices and were uninterrupted. The offices were located in different cities in Malaysia. 


\section{Interview Guide}

An interview guide was prepared based on the comments of the healthcare stakeholders (Table S1) in the Delphi study cited earlier. The interview guide was further refined following a literature review ${ }^{16-21}$ and was pilot tested for any modifications or improvements with one $\mathrm{CP}$, one nurse, and two GPs, who were not involved in this study later. Based on their feedback a few open-ended questions were further added to cover the topic under study. The complete interview guide (Table 1) was sent to all KIs before the scheduled date of the interviews.

\section{Interview Process}

Before the interviews, the KIs were detailed via email and phone call about the research objectives and reasons for interview taking. The first author, a male $\mathrm{PhD}$ candidate, was trained in interview conduct and rapport-building techniques through short courses. The first author conducted all interviews according to pre-booked appointments between June 3 and July 15, 2019 in the KIs' respective offices. As appointments were pre-booked, the interviews were conducted in comfortable settings and were uninterrupted. The KIs knew the interviewer because of their previous interactions with him during the Delphi study. A digital interview recorder was used to record the interviews and detailed written notes were taken by the researcher. As all KIs could understand and speak English fluently, interviews were conducted in the English language. Prior to beginning of interviews, the KIs were assured that they could retract or change any statement in the interview if they wished to do so. At the end of an interview, audio files were transferred to a secure, password-protected computer in possession of the research supervisor.

\section{Data Management and Analysis}

Data were managed and analyzed using NVivo plus (version 12, QSR International).

\section{Transcription, Coding, and Theme Generation}

Audio files of interviews were transcribed verbatim (in Microsoft Word) using Windows Media Player. Transcription was carried out by the first author and counterchecked by the other two authors (ASK and SK) for any errors in transcription. The supervisor (CSZ), a native, was consulted to clarify any confusion due to different dialects/ accents to avoid any misinterpretation. Transcribed Microsoft
Word documents and field notes were imported into NVivo for descriptive and interpretivist analysis.

Transcripts were coded by two authors (NM and SK) independently, based on the principles of thematic analysis and the constant comparison approach. ${ }^{22}$ Nodes depict the way in which data were carried through analysis from specific to broader codes (themes). ${ }^{23}$ Coding of the transcripts involved carefully reading and re-reading of all the transcript (data) word by word, linking and connecting texts, and highlighting various texts with different colours as per their suitability for a distinct construct or context. Any conflict in coding was resolved by involving the supervisor (CSZ) in the process to reach a consensus. Field notes helped in recalling the interview event and thus facilitated data analysis.

\section{Trustworthiness, Credibility, and Respondent Validity}

Trustworthiness or rigour in qualitative research involves credibility, transferability, confirmability, and dependability. To enhance credibility, data were collected and reported as per COREQ guidelines. Furthermore, the audio and written verbatim versions of the interviews and all transcripts were counter-checked. Coding and resulting theme generation were verified by the supervisor and two other researchers from the supervisory team. All investigators removed any disagreement on emergent themes through consensus. Furthermore, negative case analysis was utilized to substantiate the themes. To ensure transferability of this qualitative study, researchers provided thick descriptions of the phenomena and settings, including the relevant sociocultural background of the stakeholders (age, gender, education, affiliations; see Tables 2 and 3). "Respondent's validity" was used as a technique to ensure confirmability, that is, all transcribed files were sent via email to the interviewee to correct and send back if anything was not recorded or transcribed accurately. However, none reported any significant error in transcriptions. Finally, dependability was established through a well-maintained audit trail of all process logs. These logs are available from the corresponding author for auditing purposes.

\section{Theoretical Saturation}

Data saturation was viewed as achieved when no new themes were evident. Interviews were based on the plus-one principle, which states that when researchers assume that no new themes are emerging, the process of interviews may be stopped after one more interview. ${ }^{23}$ 
Table I Interview Guide

\begin{tabular}{|c|c|}
\hline & Interview Questions \\
\hline Part I & $\begin{array}{l}\text { I. Do you see any differences between the practice of community pharmacy in developed countries and in Malaysia? If yes, what are the main } \\
\text { differences? } \\
\text { 2. What are your views on collaboration of a CP with private GP clinics to provide a collaborative medication therapy management service for } \\
\text { chronic disease patients where the CP takes a more active role in patient care? } \\
\text { 3. Do you think education and counselling on medicine and disease provided by GPs is sufficient for the patients, and additional educational or } \\
\text { counselling activities would have no additional benefits? } \\
\text { 4. What would be the first practical step towards such collaboration if we move towards this goal? } \\
\text { 5. Is there any prescription review service in Malaysia? Do you think prescription review by a CP specifically trained for a chronic disease would be } \\
\text { advantageous? If yes, what might be the advantages. }\end{array}$ \\
\hline Part 2 & $\begin{array}{l}\text { I. Do you think such collaborative practice can improve patients' clinical outcomes? If yes, how? } \\
\text { 2. Do you think such collaborative practice can improve patients' outcomes, adherence, compliance, and quality of life? If yes, how? } \\
\text { 3. Do you think the service represents value for money for the government? Does it have some economic benefit? } \\
\text { 4. How could the formation of a national electronic prescription record system for chronic diseases make such activity more result-oriented/ } \\
\text { fruitful? }\end{array}$ \\
\hline Part 3 & $\begin{array}{l}\text { I. What is the most important barrier you consider relevant in the Malaysian setting and what are possible solutions? } \\
\text { 2. How can we minimize role encroachment or overlap? } \\
\text { 3. Do you think, on legal or regulatory grounds, it would be a challenging task to formulate such protocols? } \\
\text { 4. How could political will be influenced in favour of a CMTM service? } \\
\text { 5. Do you think CPs in Malaysia have the necessary knowledge and expertise/training to undertake this expanding role in medicine management } \\
\text { for chronic diseases? If not, in which area are they lacking? } \\
\text { 6. Do you think GPs' concern regarding the clinical incompetence of CPs can be minimized by providing appropriate, authentic (approved by the } \\
\text { MoH), and mandatory diplomas/training/courses on specific chronic diseases, their clinical picture, and patients, and by improving commu- } \\
\text { nication between CPs and GPs? } \\
\text { 7. Do you think collaboration in the form of a CMTM service is a threat to GP clinic business? If yes, how would you minimize/tackle this issue? } \\
\text { 8. Do GPs feel concern about sharing of patients' information and the liability of CPs? If yes, how do you suggest dealing with these concerns from } \\
\text { the perspective of either a GP or a CP? } \\
\text { 9. Whatstrategies do you feel may strengthen trust between GPs and CPs? } \\
\text { I0. How much do you think dispensing separation is linked with collaboration? Do you feel that, without dispensing separation, collaboration is } \\
\text { impossible or may be attainable? Why/how? } \\
\text { II. How do you think the public could be made aware of the role of the pharmacist? } \\
\text { Do you think CPs should be compensated for such services? Which method of payment (UHC, third-party payer, or direct billing/fee for } \\
\text { service) would be most feasible in the Malaysian setting and why? }\end{array}$ \\
\hline Part 4 & $\begin{array}{l}\text { What role would you like or consider appropriate/inappropriate to be performed by CPs in chronic disease management? } \\
\text { Do you wish to add any additional comments which may be valuable, in your experience, if we move towards this collaborative model in future? }\end{array}$ \\
\hline
\end{tabular}

\section{Ethics}

Informed consent was obtained from all KIs after providing them with information (Supplementary file S1) on the research aims and objectives. To ensure anonymity, KIs were assigned individual identification numbers. The consent included publication of anonymized responses.

\section{Results}

The first author conducted a total of 12 interviews (five CPs, five GPs, and two nurses) for a total duration of 636 mins. The average time of an interview was $50.29 \mathrm{~min}$ (longest and shortest interviews were of 77.4 mins and 34.18 mins duration, respectively). The response rate was $92 \%$ (13 KIs were contacted and 1 refused due to a schedule conflict). All interviews were conducted face to face, with the exception of one that was taken via the phone (personal preference of KI). After the ninth interview, saturation of data occurred.
However, three additional interviews were conducted to confirm data saturation

\section{Themes}

The KIs offered actionable insights on different aspects of the CMTM model which facilitated the formation of a conceptual framework outlining the way forward to a CMTM model. Five main themes emerged from the collected data. Details of the sub-themes, field notes, and insights are provided in Tables $\underline{\mathrm{S}}$ - $\underline{\mathrm{S} 7}$ for themes 1, 2, 3, 4, and 5, respectively.

\section{Demographics of the Key Informants}

Demographic data (Table 1 and Figure 1) and the diverse affiliations of KIs with various professional organizations representing GPs, CPs, and nurses in Malaysia are given in Table 2. GPs and CPs are represented equally, that is, five of each. The median age of the KIs was 50 (range = 
Table 2 Demographics and General Characteristics of Key Informants

\begin{tabular}{|c|c|c|c|c|c|}
\hline \multirow[t]{2}{*}{ Characteristics } & \multirow[t]{2}{*}{ Category } & \multicolumn{4}{|c|}{ n (\%) where, $n_{t}=12$} \\
\hline & & $G P(n=5)$ & $C P(n=5)$ & Nurse $(n=2)$ & Total \\
\hline \multirow[t]{2}{*}{ Gender } & Male & $3(25)$ & $5(4 I .7)$ & I (8.3) & $9(75)$ \\
\hline & Female & $2(16.7)$ & 0 & I (8.3) & $3(25)$ \\
\hline \multirow[t]{3}{*}{ Age group } & $36-45$ & 0 & 0 & I (8.3) & I (8.3) \\
\hline & $46-55$ & $3(25)$ & $2(16.7)$ & I (8.3) & $6(50)$ \\
\hline & $56-65$ & $2(16.7)$ & $3(25)$ & 0 & $5(4 \mid .7)$ \\
\hline \multirow{2}{*}{$\begin{array}{l}\text { Does your training curricula include interprofessional } \\
\text { collaborative practice? }\end{array}$} & Yes & $3(25)$ & $2(16.7)$ & I (8.3) & $6(50)$ \\
\hline & No & $2(16.7)$ & $3(25)$ & I (8.3) & $6(50)$ \\
\hline \multirow[t]{5}{*}{ Total experience (number of years) } & $15-20$ & I (8.3) & I (8.3) & I (8.3) & $3(25)$ \\
\hline & $2 I-25$ & $3(25)$ & 0 & 0 & $3(25)$ \\
\hline & $26-30$ & 0 & I (8.3) & I (8.3) & $2(16.6)$ \\
\hline & $31-35$ & I (8.3) & 0 & 0 & I (8.3) \\
\hline & $36-40$ & 0 & $3(25)$ & 0 & $3(25)$ \\
\hline Where did you get your training (ie, education and experience) & Local & I (8.3) & $3(25)$ & I (8.3) & $5(4 \mid .7)$ \\
\hline in your related field from? & $\begin{array}{l}\text { Both Local and } \\
\text { International }\end{array}$ & $4(33.3)$ & $2(16.7)$ & I (8.3) & $7(58.3)$ \\
\hline \multirow[t]{3}{*}{ Have you ever worked professionally with a CP? } & Yes & $4(33.3)$ & NA & $2(16.7)$ & $6(50)$ \\
\hline & No & I (8.3) & NA & 0 & I (8.3) \\
\hline & NA & - & $5(4 I .7)$ & - & $5(4 \mid .7)$ \\
\hline \multirow[t]{3}{*}{ Have you ever worked professionally with a GP? } & Yes & NA & $4(33.3)$ & $2(16.7)$ & $6(50)$ \\
\hline & No & NA & I (8.3) & 0 & I (8.3) \\
\hline & NA & $5(4 I .7)$ & - & - & $5(4 \mid .7)$ \\
\hline \multirow[t]{5}{*}{ If you are in academia, into which category do you fall? } & Professor & $\mathrm{I}(8.3)$ & I (8.3) & 0 & $2(16.6)$ \\
\hline & Associate & $2(16.7)$ & 0 & I (8.3) & $3(25)$ \\
\hline & Professor & & & & \\
\hline & Assistant Professor & 0 & 0 & 0 & 0 \\
\hline & Not in Academia & $2(16.7)$ & $4(33.3)$ & I (8.3) & $7(58.3)$ \\
\hline \multirow[t]{3}{*}{ Highest qualification/degree } & $\mathrm{PhD}$ & $2(16.7)$ & I (8.3) & I (8.3) & $4(33.3)$ \\
\hline & Master & $3(25)$ & 0 & I (8.3) & $4(33.3)$ \\
\hline & Bachelor & 0 & $4(33.3)$ & 0 & $4(33.3)$ \\
\hline
\end{tabular}

Abbreviations: GP, general practitioner; CP, community pharmacist; NA, not applicable.

40-62), while the median number of years of experience was 24 years (range $=17-39$ ).

\section{Theme I. Community Pharmacy Practice: Understanding the Difference Between Malaysia and Developed Countries}

This theme highlighted KIs' recognition of the differences in practice of community pharmacies in developed countries and Malaysia. One participant noted:

"In Malaysia our GPs can prescribe, and they can dispense, it does not happen in developed countries where $\mathrm{CP}$ offers dispensing, educational and adherence support to patients." (GP 3)
Similarly, another participant stated that:

"Of course, there's a vast difference between the practice of pharmacy in developing countries and Malaysia for example we don't have our DS and the GPs are dispensing the medication." (CP 2)

\section{Theme 2. Current Practices in Primary Care in Malaysia}

In this theme, the KIs discussed the current situation of primary care in Malaysia pertaining to law, policy, and malpractices as they relate to GPs and CPs. One participant informed the researcher that: 
Table 3 Field/Area of Expertise and Professional Associations or Affiliations of Key Informants

\begin{tabular}{|c|c|c|c|}
\hline \multirow[t]{2}{*}{ Attribute } & \multicolumn{3}{|c|}{ Category $n(\%)$ where, $N=12$} \\
\hline & GP $(n=5)$ & $C P(n=5)$ & Nurse $(n=2)$ \\
\hline \multirow[t]{3}{*}{ Field/Area of expertise* } & General Practitioner 5 (4I.7) & Pharmacist in Academia I (8.3) & Nurse in Academia I (8.3) \\
\hline & General Practitioner in Academia 3 (25) & Pharmacist in Hospital I (8.3) & $\begin{array}{l}\text { Nurse practicing with GP } \\
\qquad I(8.3)\end{array}$ \\
\hline & Family Medicine Specialist 5 (4I.7) & $\begin{array}{l}\text { Pharmacist in Community Pharmacy } \\
5(41.7)\end{array}$ & Nurse in Hospital I (8.3) \\
\hline \multirow[t]{9}{*}{$\begin{array}{l}\text { Professional associations } \\
\text { or affiliations* }\end{array}$} & Ministry of Higher Education I (8.3) & Ministry of Higher Education I (8.3) & $\begin{array}{l}\text { Ministry of Higher } \\
\text { Education } 2 \text { (16.7) }\end{array}$ \\
\hline & Ministry of Health 2 (I6.7) & Ministry of Health I (8.3) & Ministry of Health 0 \\
\hline & $\begin{array}{l}\text { Family Medicine Specialist Association } \\
\qquad \text { Malaysia } 5 \text { (4I.7) }\end{array}$ & $\begin{array}{c}\text { Malaysian Pharmaceutical Society } 4 \\
\text { (33.3) }\end{array}$ & $\begin{array}{l}\text { Malaysian Nurses } \\
\text { Association I (8.3) }\end{array}$ \\
\hline & Academy of Family Physicians Malaysia 3 (25) & $\begin{array}{l}\text { Malaysian Community Pharmacy Guild } \\
\qquad 5(4 I .7)\end{array}$ & $\begin{array}{c}\text { Malaysian Nursing Board } \\
\text { I (8.3) }\end{array}$ \\
\hline & $\begin{array}{l}\text { Federation of Private Medical Practitioners' } \\
\text { Association Malaysia } 0\end{array}$ & $\begin{array}{l}\text { Pharmacy Board/Pharmaceutical } \\
\text { Services Division } 2 \text { (16.7) }\end{array}$ & \\
\hline & Malaysian Medical Council I (8.3) & & \\
\hline & Malaysian Medical Association I (8.3) & & \\
\hline & $\begin{array}{c}\text { Medical Practitioners Coalition Association } \\
\text { of Malaysia I (8.3) }\end{array}$ & & \\
\hline & Malaysian Primary Care Network 2 (16.7) & & \\
\hline
\end{tabular}

Note: *All KIs could choose more than one option for field/area of expertise and professional associations or affiliations, if applicable.

"The GPs' side are making money out of the dispensing process, in doing so overprescribing is too high in private clinics." (CP 4)

Another KI raised concerns about GP malpractices:

"GPs are trying to use expensive new medicine, for medical condition. So, that the patient will not be able to find it elsewhere because the pharmaceutical supplier only gives those new medicines to the GP's clinic. So, they manipulate market through this practice." (CP 5)

Two KIs highlighted the need for a prescription review and utilization of the expertise of other healthcare professionals in the private sector:

"In public sector, the prescriptions are reviewed all the time, because prescription is sent to the pharmacist and pharmacist will see prescription before dispensing. No doubt, Patient safety is greatly enhanced by having a CP. It doesn't matter really, we are in private or public, the care process should be the same." (GP 4)
"It's a chronic disease so, to be just one provider, sometimes is just not enough. To drive home message, they need to hear it from many aspects, from many people." (GP 1)

Similarly, another observation was:

"CPs in Malaysia are very commercialized, dispense prescription medicines without prescription, gives wrong advice, promote supplements over medicine/nonevidence based therapy, doing lab tests etc. Currently there are cases of cardiac failure being diagnosed and treated for walk in patients without consulting a GP/Doctor resulting GPs low trust in the pharmacists." (GP 3)

\section{Theme 3. Potential Advantages of CP-GP Collaboration in Chronic Disease Management}

The KIs detailed the advantages of $\mathrm{CP}-\mathrm{GP}$ collaboration for patients, professionals, and government. A participant informed the researcher that: 


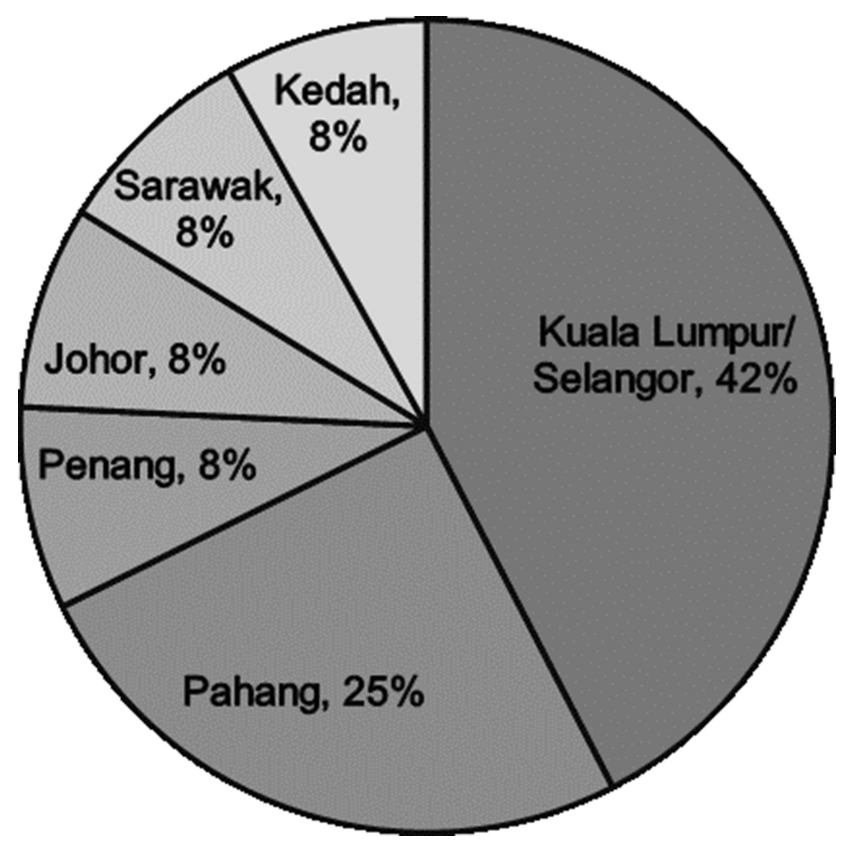

Figure I Geographical diversity of key informants across Malaysia.

"The healthcare system has become more complex in chronic care. I think $\mathrm{CP}$ should take their active role. We are not supporting one another's role, but we should be collaborative and promote patient safety as errors in prescription by GP can be picked up by CP." (GP 4)

Another participant was of the view:

"We see this from the business angle, that's why the trust is difficult to develop but if you see from the patients angle you want to give the benefit to patient through this collaboration." (GP 5)

Finally, a third concluded:

"Collaboration between GP and CP will help to improve the compliance of many of the chronic diseases and it would happen when it's a teamwork, with multidisciplinary team." (GP 1)

\section{Theme 4. Major Barriers to CP-GP Collaboration}

The KIs identified a range of barriers that impede collaboration in the Malaysian context, such as absence of DS, GPs' conflict of interest, lack of awareness of CPs role, and absence of trust between the two stakeholders. This may be evidenced from the following comment by a KI:

"I think the biggest threat to the private GPs will be reduction of income. GPs do not make much money from consultation under the current consultation rate. They make money from dispensing drugs. That is the main reason why they do not agree to the 'separation of function'." (GP 1)

Another participant poignantly observed that:

"Sending patients to two different places (CP and GP) would practically fragment the healthcare system and suffocate patients." (GP 4)

Expressing concern, a participant noted that:

"There will be role encroachment of GPs, patients once referred to pharmacies would not be back." (GP 3)

\section{Theme 5. Way Forward Towards Enhanced CP-GP Collaboration in Malaysia Following a Collaborative Medication Therapy Management Model}

Generally, the KIs viewed offering certain clinical roles in chronic disease management to CPs positively, such as giving advice on the cost-effectiveness of prescriptions, providing prescription/medicine-use reviews and education, and offering adherence support. In this context, an interviewee said that:

"Definitely, prescription review, advice on cost effective prescribing and adherence support are the roles which the pharmacists can play, and you know about half of the medication errors lead to prescription errors. But dose adjustment has to be done collaboratively. The pharmacy needs to contact GPs and discuss with the GPs in terms of dose adjustments." (GP 4)

The GPs also feel that Malaysia is not yet ready for DS because of an inadequate number of pharmacies, CPs and operating hours. They feel that it will discomfort patients, especially in the areas where there are few pharmacies, for instance in Shah Alam, Sabah, and Sarawak. Furthermore, dispensing GPs already charge nominal fees as low as 15MYR. Here, then, DS would result in a hike in GPs' consultation fees, which would have adverse implications for the private healthcare sector. KIs, especially CPs, declared these views as ignorant of the facts and characterized them as old rhetoric which hampered the proposal of CPs' role expansion in 1990 when there were not enough CPs. However, it is no more valid today, they reported. Participants noted that the growth of pharmacies has made community pharmacies conveniently available to the public 
and Malaysia has already met the WHO required number of pharmacists as per population needs. Furthermore, CPs reported not having patients at the moment. If CMTM-type services were in operation, the number of hours would automatically be extended.

In this context, participants noted the following:

"Separation of function is the way forward. But problems with remuneration for both GPs and CPs must be addressed through universal coverage under the national health financing scheme which is long overdue." (GP 1)

One of the KIs suggested that the most feasible remuneration method for CMTM in the Malaysian setting would be either third-party payer or universal health coverage:

"At present, I think the universal health coverage, or the thirdparty payer will be appropriate because the insurance company can pay money to fund this type of collaboration.” (CP 4)

Thus, this study suggests that the most feasible remuneration model for CMTM in the Malaysian setting will be either thirdparty payer or universal health coverage. This is based on the following view, that was also reflected in other interviews:

"We can follow the models like, in Australia ... or in UK, what, they also have the non-dispensing pharmacist there, at least we should try." (CP 4)

Two KIs opted for a win-win situation. One noted:

"To produce a collaborative working environment, we should aim for a win-win situation for everyone, we do not want GP or CP to suffer, and we want the patients to benefit from all this." (CP 2)

The other stated:

"All the communications and all the roles must be defined clearly, both GP and CP should be compensated ... There is something that is very positive about CMTM model it is for the benefits of Malays." (GP1)

Concept mapping of the various propositions of KIs, including the positively viewed role of CPs leads to a conceptual framework of the way forward towards the CMTM model in Malaysia, as shown in Figure 2 (the coding tree has been provided in Figure S2).

\section{Discussion}

Given the above, it seems logical that different healthcare professionals should collaborate to offer patients a combined set of expertise. However, practically, this first needs a behavioural change in the way these stakeholders perceive each other. The theory of reasoned action highlights that collaboration will be successful only if it is viewed as "useful" by both partners. ${ }^{24}$ The CMTM model conceived in this study was perceived as being useful by all stakeholders; however, complexity arises because of conflicts of interest, differential positioning, and powers and stakes of different professionals within the healthcare system.

Furthermore, role theory covers the definition, clarification, and labelling of roles assumed in society. These labels augment formation of assumptions which may lose validity with the passage of time. In this context, GPs in Malaysia used to perceive the role of CPs as retailers and that stereotypical image hinders successful collaboration even today. GPs' reluctance to collaborate with CPs may be resolved with clarity in defining the new roles of CPs. For instance, in the UK, initially GPs were against the idea of collaborative practices because of their perception of CPs as "shopkeepers". However, after initial phases of social interaction, they came to value the contributions of CPs in improving adherence and quality in the medicineuse process. $^{25}$ Furthermore, based on the positive experience with CPs, a recent panel of healthcare stakeholders in the UK recommended further expansion of the collaboration between CPs and GPs to promote community pharmacy services for long-term conditions. ${ }^{26}$

On the other hand, the decades-old conflict regarding dispensing separation in Malaysia is still ongoing, and GPs are not ready to give away this right to pharmacists. This could be a possible reason why the Ministry of Health, Malaysia is still reluctant to support such an initiative. Further action on this remains stymied because of the higher stakes of the GPs in the healthcare system and the lack of proactive lobbying from the CPs' side, whereby they could claim DS as their fundamental right and point out that it is now an internationally accepted and preferred practice. $^{25}$ However, we agree with this view only to the extent that future policy regarding DS in Malaysia should be comprehensive as it may hit the financial interests of GPs.

Furthermore, remuneration models for collaborative practices vary from country to country. For instance, the Australian model of remuneration entails a win-win situation and reimburses both GPs (for referrals) and CPs (for services). ${ }^{27}$ However, in the Malaysian context, as the results suggest, choosing a method of remuneration is not straightforward. In effect, diverse factors influence the choice of remuneration method; for instance, budget 


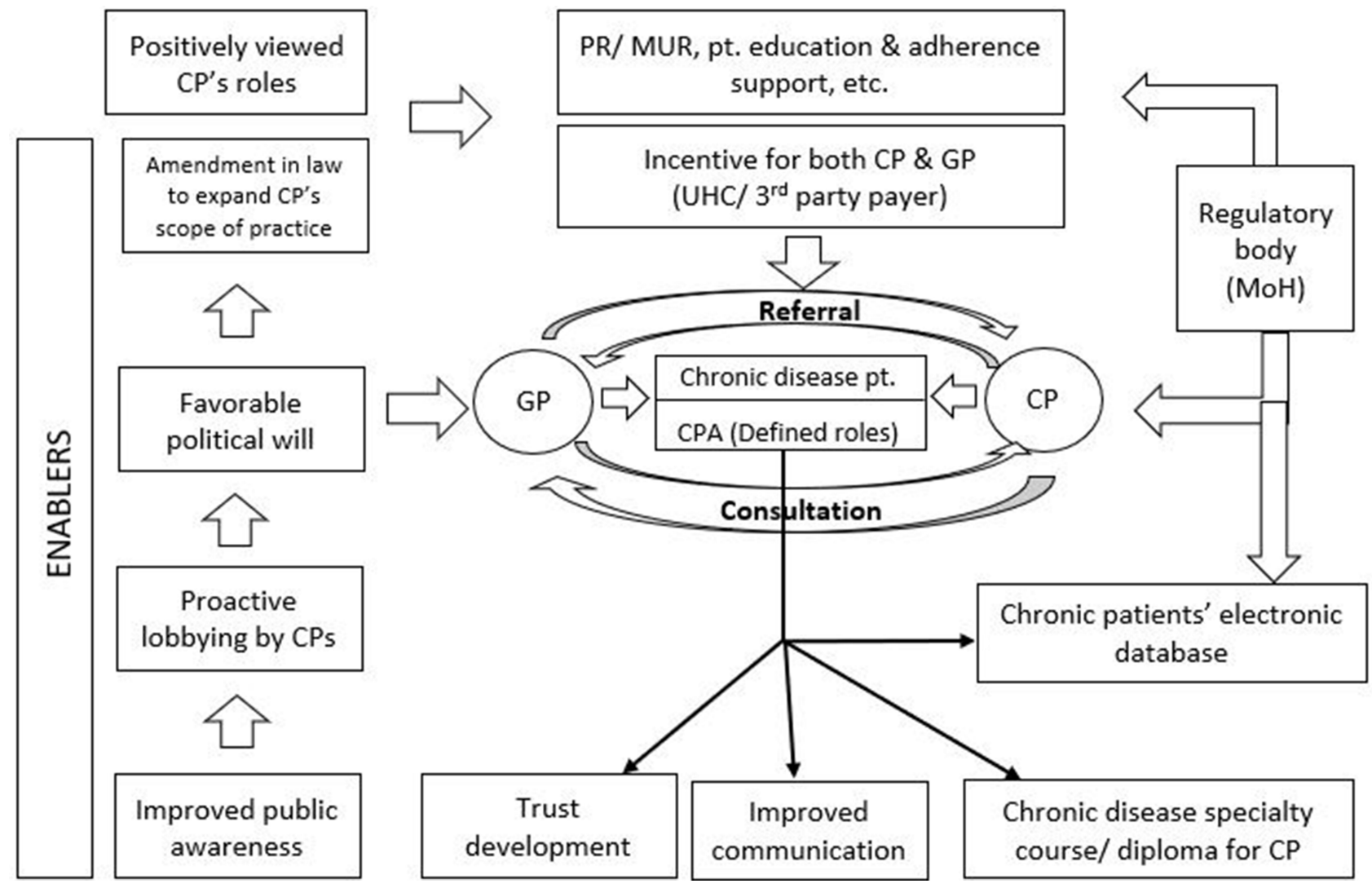

Figure 2 Concept mapping of the way forward towards a collaborative medication therapy management model in Malaysia.

Abbreviations: CP, community pharmacist; GP, general practitioner; PR/MUR, prescription review/medicine-use review; CPA, collaborative practice agreement; UHC, universal health coverage; MoH, Ministry of Health.

constraints, payers' perspectives, awareness levels, and value of the services being provided can be seen as some of the most pressing issues.

The findings of this study may be broadly correlated with those of a recent qualitative study in Brazil, where a similar exercise was carried out using relevant healthcare stakeholders to explore new models of care with an aim to involve CPs in medicine management of chronic diseases. ${ }^{28}$ Another study in Canada engaged healthcare stakeholders to identify various enablers of effective integration of community pharmacy with primary care. This study offered similar results to ours regarding various discordant perceptions, concerns, and conflicts of interest. ${ }^{29}$ However, we noted one formidable difference: nearly all developed countries have a perfect DS system in practice whereas, in Malaysia, this issue has emerged as a major barrier to collaboration. An important point to establish here is that the barriers to and facilitators of collaboration identified in this study are somehow similar to those enlisted in a recent systematic review that summarized factors affecting collaboration between CPs and GPs around the globe. ${ }^{30}$
Results of this study not only confirmed the findings of the previous Delphi study ${ }^{14}$ but also explored the way forward for a number of barriers erected previously. For instance, the current study implied that CPs' role expansion in the proposed CMTM model might not be a comfortable change for all. A few GPs also recorded pertinent concerns, for instance regarding CPs' lack of clinical competencies. However, these concerns, if addressed, could result in building trust. The KIs in this study suggested that special training (an accredited speciality course or a diploma in specific chronic disease management) and extra accreditation requirements for CPs may resolve this issue. Literature also supports the finding that CMTM type of collaborative services require greater clinical knowledge and skills for specific chronic diseases. ${ }^{31}$ Professional organizations representing pharmacists, such as the Malaysian Pharmaceutical Society and the Community Pharmacy Guild Malaysia, can play a leading role in training CPs for a more clinical role in chronic disease management. Similarly, this framework offers key solutions to various problems in the minds 
of GPs; in particular, it addresses key monetary concerns of GPs by proposing a possible win-win situation in the form of third-party payer or universal health coverage.

Regarding policy, the concerned authorities in Malaysia should take advantage of the framework of the way forward to a CMTM model and consider changing the way policy governs the scope of practice in community pharmacy. For instance, the framework may be used as an outline upon which to build and further develop a more robust framework as more input is received from additional stakeholders in the process.

The KIs also emphasized that future medical and pharmacy education should focus on and practise interprofessional collaboration right from the beginning to eradicate the silo-mindset that is at the root of this issue. This proposition is also in-line with the findings of a recent study that used combined pharmacotherapy workshops for medical and pharmacy students. Post-intervention results indicated significant positive improvements in attitude towards interprofessional collaboration. ${ }^{32}$

A self-sustained collaborative model needs external forces, internal motivations, and a win-win situation for all members in a team. In this context, political will can act as an external force which can ensure sustained collaboration in primary care. The results of this study suggest that to influence political will, firstly, political leadership and bureaucracy need to understand the economic benefits of such collaboration through an evidence-based finding; furthermore, the GPs in Malaysia should acknowledge the benefits of having a CP in the chronic care team. Secondly, public awareness of the advantages of the CMTM model needs to be improved. This conceptual framework may be advocated and advertised for this purpose in print and social media.

Finally, a more extensive pilot study merits consideration as a natural extension of this exploratory study to evaluate the ground dynamics of collaborative practice. For instance, in a big city, a chain of pharmacies may be connected with GPs to document the benefits and risks.

\section{Strengths and Limitations}

The study had the following strengths:

The study, one of its kind in the Malaysian setting, recruited a geographically diverse panel of healthcare stakeholders comprising of the leadership of various associations, guilds, societies, and alliances in the medical, nursing and pharmacy professions, academia and Ministry of Health, Malaysia, to offer a framework for enhanced interprofessional collaboration between GPs and CPs in primary care. The way forward to the successful CMTM model conceived in this study fills an important gap in the literature and presents possibilities and advantages of an avenue of collaboration between the GP and $\mathrm{CP}$ in primary care in Malaysia operating through community pharmacies. The study highlighted GPs' concerns and also discussed trust-building measures between CPs and GPs. The findings may be applicable to other countries in the Asia Pacific region in a similar situation regarding interprofessional collaboration in primary care.

The limitations of the study include:

Because transcribing the interviews was excessively timeconsuming, it was not practically possible to precisely infer where the data saturation point occurred. However, three additional interviews compensated for this limitation. English was not the first language of either the interviewer or the interviewees. Although the KIs were well-qualified they had different English accents to the interviewer. This aspect might have produced some bias in transcribing. However, the supervisor was Malay, thus it was partially compensated for when the transcribing was counter-checked. The KIs were taken from an already formed panel and no new expert was added. Though it is logical to have experts who knew the background of this study and had participated in the Delphi phase, the addition of new members (outside of the Delphi panel) could further enrich data. Neither patients nor members of the public were taken on board to explore the issue from their perspectives. However, not involving these people was deliberate because many studies have been published describing the favourable views of the public/patients regarding extending the role of CPs.

\section{Conclusion}

This study engaged Malaysian healthcare stakeholders to offer a framework of the way forward for enhancing collaboration between CPs and GPs in primary care settings for chronic diseases. Generally, the KIs were interested in such collaboration and viewed the many roles of CPs in chronic patient care positively. The framework of the way forward should, then, include: defined protocols for collaborative practices; incentives for both CPs and GPs; revision of relevant legislation to grant $\mathrm{CPs}$ an active role in chronic care; and, regulatory checks under the leadership of the Ministry of Health. The authors of this study suggest that Malaysian primary healthcare must also encompass new models of care based on a collaborative working philosophy to utilize its strength (the $\mathrm{CPs}$ ) today to deliver high-quality patient care tomorrow. 


\section{Data Sharing Statement}

All the underlying data have been provided in the Supplementary Materials open to the public. Furthermore, the data may also be accessed on request to the corresponding authors.

\section{Ethical Approval}

Medical Research Ethical Committee, Ministry of Health, Malaysia granted ethical approval of the study (ref: KKM/ NIHSEC/P16-1632, NMRR-16-1775-32273) in addition to the approval of the International Islamic University Malaysia, Research Ethics Committee (ref: IIUM/308/C/ 1/G1527859) (Supplementary Materials).

\section{Disclaimer}

This article has not been previously published in any journal; however, it was part of the $\mathrm{PhD}$ thesis that was submitted to the International Islamic University, Malaysia, Online Repository by the first author. The authors have full permission from the supervisor (Dr Che Suraya Zin) and university to publish this chapter as a scholarly manuscript.

\section{Acknowledgments}

Million thanks to Dr Shazia Jamshed, Associate Professor, Universiti Sultan Zainal Abidin UniSZA, for her valuable input in revising the draft. The authors are immensely grateful to Mr. Behzad Taimur, a Public Health Researcher at Lahore University of Management Sciences (LUMS), for revising the manuscript for improvements in the English language and expression. We are also indebted to Ms. Saira Zulfiqar, a medical writer, for her kind help and valuable time to improve the contents of the manuscript.

\section{Funding}

None to disclose.

\section{Disclosure}

The authors report no conflicts of interest in this work.

\section{References}

1. Ministry of Health M. Health Facts 2017 (Reference Data for 2016); 2017. Available from: https://www.moh.gov.my/moh/resources/ Penerbitan/Penerbitan\%20Utama/HEALTH\%20FACTS/HEALTH\% 20FACTS\%202017.pdf. Accessed March 21, 2021.

2. Grover A, Joshi A. An overview of chronic disease models: a systematic literature review. Glob J Health Sci. 2014;7(2):210-227. doi:10.5539/gjhs.v7n2p210
3. Reeves S, Pelone F, Harrison R, Goldman J, Zwarenstein M. Interprofessional collaboration to improve professional practice and healthcare outcomes. Cochrane Database Syst Rev. 2017;6: CD000072. doi:10.1002/14651858.CD000072.pub3

4. Sinha R, Pati S. Addressing the escalating burden of chronic diseases in India: need for strengthening primary care. J Fam Med Prim Care. 2017;6(4):701-708. doi:10.4103/jfmpc.jfmpc_1_17

5. Jaafar S, Mohd Noh K, Othman NH, Healy J. Malaysia Health System Review. Vol. 3. 2013.

6. Mohd-Tahir N-A, Paraidathathu T, Li S-C. Quality use of medicine in a developing economy: measures to overcome challenges in the Malaysian healthcare system. SAGE Open Med. 2015;3 (February2016):205031211559686. doi:10.1177/2050312115596864

7. $\mathrm{MoH}$ Malaysia. National Strategic Plan for Non-Communicable Disease (NSP-NCD) 2016-2025; 2016.

8. Thomas RVA. Consumers' perception of generic medicines in community pharmacies in Malaysia. South Med Rev. 2009;2 (2):20-23.

9. Thomas S, Beh L, Bin NR. Health care delivery in Malaysia: changes, challenges and champions. J Public Health Africa. 2011;2 (2):93-97. doi:10.4081/jphia.2011.e23

10. Sebastian A, Alzain MA, Asweto CO, et al. The Malaysian health care system: ecology, plans, and reforms. Fam Med Community Health. 2016;4(3):19-29. doi:10.15212/FMCH.2016.0101

11. Quek D The Malaysian health care system: a review; 2014. Available from: https://www.researchgate.net/publication/237409933_The_ Malaysian_Health_Care_System_A_Review. Accessed March 21, 2021.

12. Chua SS, Lim KP, Lee HG. Utilisation of community pharmacists by the general public in Malaysia. Int J Pharm Pract. 2013;21(1):66-69. doi:10.1111/j.2042-7174.2012.00219.x

13. Hassali MA, Li S, M Vivienne, See OG. Pharmacy practice in Malaysia. Pharm Pract Res. 2014;44(3):125-128.

14. Mubarak N, Hatah E, Aris MAM, Shafie AA, Zin CS. Consensus among healthcare stakeholders on a collaborative medication therapy management model for chronic diseases in Malaysia; a Delphi study. PLoS One. 2019;14(5):e216563. doi:10.1371/journal. pone. 0216563

15. Nik J, Lai PS, Ng CJ, Emmerton L. A qualitative study of community pharmacists' opinions on the provision of osteoporosis disease state management services in Malaysia. BMC Health Servi Res. 2016;16:448.

16. Smith MA, Spiggle S, McConnell B. Strategies for community-based medication management services in value-based health plans. Res Soc Adm Pharm. 2016. doi:10.1016/j.sapharm.2016.01.005

17. Löffler C, Koudmani C, Böhmer F, et al. Perceptions of interprofessional collaboration of general practitioners and community pharmacists - a qualitative study. BMC Health Serv Res. 2017:1-7. doi:10.1186/s12913-017-2157-8.

18. Van C, Costa D, Abbott P, Mitchell B, Krass I. Community pharmacist attitudes towards collaboration with general practitioners: development and validation of a measure and a model. BMC Health Serv Res. 2012;12:320. doi:10.1186/1472-6963-12-320

19. Saw PS, Nissen L, Freeman C, Wong PS, Mak V. Exploring the role of pharmacists in private primary healthcare clinics in Malaysia: the views of general practitioners. J Pharm Pract Res. 2017;27-33. doi:10.1002/jppr.1195

20. Freeman C, Cottrell W, Kyle G, Williams I, Nissen L. Integrating a pharmacist into the general practice environment: opinions of pharmacist's, general practitioner's, health care consumer's, and practice manager's. BMC Health Serv Res. 2012;12(1):229. doi:10.1186/ 1472-6963-12-229

21. Supper I, Catala O, Lustman M, Chemla C, Bourgueil Y, Letrilliart L. Interprofessional collaboration in primary health care: a review of facilitators and barriers perceived by involved actors. 2014:1-12. doi:10.1093/pubmed/fdu102 
22. Braun V, Clarke V. Using thematic analysis in psychology. Qual Res Psychol. 2006;3(2006):77-101. doi:10.1191/1478088706qp063oa

23. Bazeley P. Analysing qualitative data: more than 'identifying themes. Malaysian J Qual Res. 2009;2(January 2009):6-22. doi:10.1017/ CBO9781107415324.004

24. Trafimow D. The theory of reasoned action: a case study of falsification in psychology. Theory Psychol. 2009;19(4):501-518. doi: $10.1177 / 0959354309336319$

25. Latif A, Waring J, Watmough D, et al. Examination of England's New Medicine Service (NMS) of complex health care interventions in community pharmacy. Res Soc Adm Pharm. 2016;12(6):966-989. doi:10.1016/j.sapharm.2015.12.007

26. Hindi AMK, Schafheutle EI, Jacobs S. Community pharmacy integration within the primary care pathway for people with long-term conditions: a focus group study of patients', pharmacists' and GPs' experiences and expectations. BMC Fam Pract. 2019;20(1):1-15. doi:10.1186/s12875-019-0912-0

27. Jokanovic N, Tan EC, Sudhakaran S, et al. Pharmacist-led medication review in community settings: an overview of systematic reviews. Res Social Adm Pharm. 2016. doi:10.1016/j.sapharm.2016.08.005

28. Detoni KB, Do NMMG, Oliveira IV, Alves MR, Gonzáles MM, Oliveira DR. Comprehensive medication management services in a brazilian specialty pharmacy: a qualitative assessment. Int $J$ Pharm Pharm Sci. 2017;9(3):227-232. doi:10.22159/ijpps.2017v9i3.16398
29. Lake JD, Rosenberg-yunger ZRS, Dainty KN, Den Baumen TRV, Everall AC, Guilcher SJT. Understanding perceptions of involving community pharmacy within an integrated care model: a qualitative study. BMC Heal Serv Res. 2020;20(396):1-9. doi:10.1186/s12913020-05237-y

30. Bollen A, Harrison R, Aslani P, van Haastregt JCM. Factors influencing interprofessional collaboration between community pharmacists and general practitioners-A systematic review. Health Soc Care Community. 2018;(November):1-24. doi:10.1111/hsc.12705

31. Bookey-Bassett S, Markle-Reid M, Mckey CA, Akhtar-Danesh N. Understanding interprofessional collaboration in the context of chronic disease management for older adults living in communities: a concept analysis. J Adv Nurs. 2017;73(1):71-84. doi:10.1111/ jan. 13162

32. Seselja Perisin A, Mestrovic A, Bozic J, et al. Interprofessional pharmacotherapy workshop: intervention to improve health professionals' and students' attitudes towards collaboration between physicians and pharmacists. J Interprof Care. 2019;33(5):456-463. doi:10.1080/13561820.2018.1541875
Risk Management and Healthcare Policy

\section{Publish your work in this journal}

Risk Management and Healthcare Policy is an international, peerreviewed, open access journal focusing on all aspects of public health, policy, and preventative measures to promote good health and improve morbidity and mortality in the population. The journal welcomes submitted papers covering original research, basic science, clinical \& epidemiological studies, reviews and evaluations,

\section{Dovepress}

guidelines, expert opinion and commentary, case reports and extended reports. The manuscript management system is completely online and includes a very quick and fair peer-review system, which is all easy to use. Visit http://www.dovepress.com/testimonials.php to read real quotes from published authors. 